\title{
POLICY EVALUATION OF NINE-YEARS LEARNING COMPULSORY OF BASIC EDUCATION: OBJECTIVES CONTEXT
}

\author{
Lia Amalia \\ Universitas Negeri Jakarta, Jakarta, Indonesia \\ Email: bazlin10@gmail.com \\ Neti Karnati \\ Universitas Negeri Jakarta, Jakarta, Indonesia \\ Email: netikarnati@gmail.com \\ Nurhatatti Fuad \\ Universitas Negeri Jakarta, Jakarta, Indonesia \\ Email: nurhatatifuad@gmail.com \\ DOI: 10.35445/alishlah.v12.i2.226 \\ Accepted: August $16^{\text {th }}, 2020$. Approved: October $28^{\text {th }}, 2020$ \\ Published: December 30 ${ }^{\text {th }}, 2020$
}

\begin{abstract}
The purpose of this research was to evaluate the policy of the nine-year learning compulsory of basic education from the objectives context. The research method used evaluation research approach through descriptive qualitative method. The data collection methods used interviews, observations, and documents. The data analysis technique used three stages, namely data reduction, data presentation, discussion, and drawing conclusions. The findings conclude that the objective of the nine-year compulsory education is in accordance with the government rule from the central and local governments. The methods used by the Serang government in achieving the goal of the nine-year compulsory education are the use of both natural and human resources, the participation of all parties in a comprehensive manner to carry out educational activities, and an interactive system of coordination between all parties. The implication of this research is seen in the implementation of education and management of education policies in the city of Serang.
\end{abstract}

Keywords: Policy, Basic Education, Compulsory Learning 


\title{
EVALUASI KEBIJAKAN WAJIB BELAJAR PENDIDIKAN DASAR SEMBILAN TAHUN: KONTEKS TUJUAN
}

\begin{abstract}
Abstrak
Tujuan dari penelitian ini adalah untuk mengevaluasi kebijakan wajib belajar pendidikan dasar 9 tahun dalam konteks tujuan. Metode penelitian yang digunakan adalah pendekatan penelitian evaluasi dengan metode deskriptif kualitatif.. Adapun metode pengumpulan data menggunakan wawancara, observasi, dan dokumen. Teknik analisis data menggunakan tiga tahap yaitu reduksi data, penyajian data, diskusi, dan penarikan kesimpulan. Hasil temuan menyimpulkan bahwa tujuan wajib belajar 9 tahun sesuai PP dari pusat dan daerah. Cara yang digunakan pemerintah kota Serang dalam mencapai tujuan wajib belajar 9 tahun adalah pemanfaatan sumber daya baik alam maupun manusia, keikutsertaan semua pihak secara komprehensif untuk menjalankan aktivitas pendidikan, dan sistem koordinasi yang interaktif di antara semua pihak. Implikasi penelitian ini terlihat pada pengutan penyelenggaraan pendidikan dan pengelolaan kebijakan pendidikan di kota Serang.
\end{abstract}

Kata Kunci: Kebijakan, Pendidikan Dasar, Wajib Belajar

\section{PENDAHULUAN}

Wajib belajar pendidikan dasar 9 tahun merupakan kebijakan pemerintah Indonesia. Kebijakan tersebut muncul bertujuan untuk melakukan pemerataan kualitas pendidikan di Indonesia sehingga taraf kesejahteraan kehidupan masyarakat Indonesia juga meningkat. Selain itu, kebijakan tersebut muncul disebabkan karena berbagai kondisi yang terjadi di lapangan, seperti; 1) ada $80 \%$ lebih angkatan kerja hanya berpendidikan SD, tidak berpendidikan, dan SMP tidak tamat. 2) kebijakan wajardikdas 9 tahun akan meningkatkan mutu SDM dan dapat memberikan nilai tambah pada pertumbuhan ekonoml, 3) pendidikan yang tinggi dapat mempengaruhi partisipasi dan kontribusi pada sektor-sektor yang produktif. 4) Kebijakan wajardikdas 9 tahun dapat meningkatkan kematangan dan keterampilan siswa, 5) pelaksanaan wajardikdas 9 tahun akan meningkatkan umur kerja minimum dari 10 sampai 15 tahun (Hidayat, 1994). Kebijakan Wajardikdas 9 tahun saat ini telah dijabarkan dalam Peraturan Pemerintah Nomor 47 Tahun 2008.

Tujuan wajardikdas yang tercantum dalam Peraturan Pemerintah Nomor 47 Tahun 2008 yaitu memberikan pendidikan minimal bagi warga negara Indonesia untuk dapat mengembangkan potensi dirinya agar dapat hidup mandiri di dalam masyarakat atau melanjutkan pendidikan ke jenjang yang lebih tinggi (Pemerintah Republik Indonesia, 2008). Oleh karena itu, pemerintah kota Serang menetapkan tujuan dari penyelenggaraan program wajib belajar 9 tahun sesuai dengan kebutuhan saat ini, sehingga masyarakat di Serang mampu menghadapi 
Al-Ishlah: Jurnal Pendidikan - ISSN: 2087-949o (p); 2597-940X (e)

Vol. 12, No. 2 (2020)

tantangan global. Untuk mewujudkan hal tersebut membutuhkan evaluasi kebijakan yang dilakukan secara berkala.

Dari hasil observasi lapangan pada bulan April 2017 melalui kegiatan wawancara dengan Kepala Dinas Pendidikan Kota Serang disimpulkan bahwa tujuan yang ingin dicapai dari kebijakan wajib belajar pendidikan dasar 9 tahun saat ini belum tercapai secara komprehensif. Artinya bahwa masih ada permasalahan dalam penyelenggaraan pendidikan tingkat dasar. Padahal tujuan merupakan bagian yang sangat penting untuk mengetahui keberhasilan kebijakan Wajardikdas 9 tahun. Fungsi dan tujuan penyelenggaraan wajib belajar 9 tahun. Dalam PP No.47 Tahun 2008 dikatakan bahwa wajib belajar berfungsi mengupayakan perluasan dan pemerataan kesempatan memperoleh pendidikan yang bermutu bagi setiap warga negara Indonesia. Sedangkan wajib belajar bertujuan memberikan pendidikan minimal bagi warga negara Indonesia untuk dapat mengembangkan potensi dirinya agar dapat hidup mandiri di dalam masyarakat atau melanjutkan pendidikan ke jenjang yang lebih tinggi.

Namun kondisi ideal dari fungsi dan tujuan wajib belajar 9 tahun tersebut belum tercapai maksimal. Hal ini disebabkan karena beberapa faktor penghambat dari data yang diperoleh yaitu 1) persentase penduduk miskin dan garis kemiskinan masing cukup tinggi, dan 2) angka pertisipasi sekolah (APS) Kota Serang tahun 2016 masih cukup rendah. Dari kajian data survei ke 4 sekolah dasar dan 4 sekolah menengah di Kecamatan Kasemen dan Cipocok Jaya melalui diskusi dengan kepala sekolah yang disimpulkan bahwa banyak orang tua siswa yang berpandangan terhadap anak-anak mereka yang sekolah. Informasi dari sekolah memaparkan bahwa Ketika sekolah melakukan pertemuan dengan ornag tua, banyak orang tua yang kesulitan untuk biaya sekolah. Bagi orang tua, banyak yang sekolah sampai pendidikan tinggi tetapi mereka tetap kesulitan dalam bekerja. Jadi para orang tua berpandangan bahwa sebaiknya anak-anak mereka bisa membantu orang tua bekerja. Fenomena ini berkembang dalam kehidupan masyarakat di Kota Serang. Banyak orang tua belum memahami sepenuhnya tentang kebutuhan pendidikan bagi anak-anak mereka dan lebih cenderung menyuruh anak-anak mereka untuk ikut bekerja membantu mereka daripada sekolah. Kemampuan ekonomi yang sulit untuk membiayai pendidikan anak-anak mereka juga menjadi salah satu penghambat untuk bersekolah. Selain itu, mereka memiliki keyakinan bahwa mengikuti sekolah hanya menghabiskan waktu tanpa adanya perbaikan hidup. Keyakinan ini seolah-olah menjadi kenyataan ketika beberapa diantara lulusan masih menganggur. Bagi sebagian daerah lain di kota Serang, jarak tempuh (Lu, 2018) menjadi salah satu kendala untuk siswa bisa sampai ke sekolah sehingga hal tersebut cukup berdampak pada pemerataan penyelenggaraan kebijakan wajib belajar 9 tahun di Kota Serang. 
Vol. 12, No. 2 (2020)

Kondisi penghambat tersebut menjadi masalah dalam pencapaian tujuan dari penyelenggaraan wajib belajar pendidikan dasar 9 tahun di Kota Serang. Hal ini seharusnya menjadi orientasi utama pemerintah untuk merencanakan berbagai cara dalam mencapai tujuan. Evaluasi penetapan tujuan penyelenggaraan wajib belajar 9 tahun menjadi prioritas yang sangat penting untuk mengetahui keberhasilan pencapaian pendidikan. Jin \& Zhang (2008) menyimpulkan bahwa negara tidak menetapkan semua wilayah wajib melaksanakan pendidikan wajib 9 tahun karena pertimbangan kekuatan nasional tertentu. Anti (2015) menyimpulkan bahwa faktor-faktor yang mempengaruhi kebijakan wajib belajar 9 tahun dipekanbaru pada tahun 2012 adalah standar dan tujuan, komunikasi, karakterisrik agen pelaksana, kondisi sosial dan ekonomi dan disposisi. Penelitian ini hanya membahas wajardikdas dari konteks tujuan saja dan tidak menyeluruh konteks kebijakan. (Mugiri \& Lestari, 2013) menyimpulkan bahwa kegiatan evaluasi seperti Dana BOS di Kota Pekalongan seharusnya memiliki instrument yang baku. Berbeda hal dengan evaluasi Dana BOS di Kabupaten Mamuju. Hasil evaluasi menunjukkan bahwa penggunaan Dana BOS sudah cukup baik walaupun masih terdapat kekurangan dan kelebihan (Akbar, 2016). Sedangkan kendala dalam komponen produk adalah kualitas prestasi belajar non akademik (Darma, 2019).

Stufflebeam dan Shinkfield menyarankan evaluasi produk yang dilakukan untuk empat aspek evaluasi: dampak, efektivitas, keberlanjutan, dan kemampuan pengangkutan. Proses pengambilan keputusan dilakukan dengan membandingkan temuan / fakta yang terkandung dalam konteks, input, proses dan standar produk atau kriteria yang telah ditetapkan sebelumnya (Warju, 2016). Temuan menunjukkan bahwa kelompok sekolah kesejahteraan ini berfokus pada pendidikan berkualitas dengan menggunakan berbagai cara, seperti teknologi canggih, komunikasi yang efektif, pembelajaran relevan serta strategi belajar mengajar; Namun, ditemukan bahwa guru lebih fokus pada pekerjaan teoritis dan hafalan, yang memberikan tekanan pada siswa dan memiliki efek negatif pada kemampuan intelektual mereka. Selain itu, ada kekurangan ruang yang layak, lingkungan yang efektif dan sekolah-sekolah terletak di gedung sewaan (Aziz, Mahmood, \& Rehman, 2018).

Dari penelitian terdahulu diketahui bahwa evaluasi suatu program atau kebijakan dilakukan secara komprehensif untuk pelaksanaan program tersebut. Namun pada penelitian yang dilakukan ini berorientasi pada evaluasi hasil implementasi kebijakan wajib belajar 9 tahun di Kota Serang yang berlandaskan pada PP No.47 tahun 2008 dan RPJMD Kota Serang secara komprehensif. Penelitian ini dipahami melalui produk yang telah dihasilkan dari kebijakan wajib belajar pendidikan dasar 9 tahun. Hal ini memberikan nilai berbeda dengan penelitian sebelumnya. 
Vol. 12, No. 2 (2020)

Berdasarkan pada paparan tersebut dapat diketahui bahwa tujuan dari penelitian ini adalah untuk mengevaluasi kebijakan wajib belajar pendidikan dasar 9 tahun di Kota Serang. Bagi dinas pendidikan Kota Serang, hasil penelitian ini diharapkan dapat dijadikan sebagai bahan masukan bagi sekolah dan Dinas Pendidikan Kota Serang dalam rangka merancang berbagai cara untuk mencapai keberhasilan tujuan dari implementasi kebijakan wajib belajar pendidikan dasar 9 tahun.

\section{METODE PENELITIAN}

Penelitian ini mengggunakan pendekatan penelitian evaluasi dengan metode deskriptif kualitatif. Penelitian kualitatif mengkaji fenomena sosial yang terjadi di lapangan sesuai dengan konteks (Ary, Jacobs, Sorensen, \& Razavieh, 2010). Dengan demikian, penelitian ini mengevaluasi implementasi kebijakan wajib belajar pendidikan dasar 9 tahun dari konteks tujuan yang telah ditetapkan pemerintah Kota Serang. Teknik dan prosedur pengumpulan data dalam penelitian ini dilakukan secara sistematis dengan menggunakan teknik wawancara, observasi dan dokumen. Adapun paparan untuk setiap teknik pengumpulan data adalah:

1. Wawancara dan FGD, dilakukan terhadap sumber informasi (informan) yaitu kepala Dinas Pendidikan kota Serang dan Kepala Sekolah di Kecamatan Kasemen dan Kecamatan Cipocok Jaya.

2. Observasi / pengamatan lapangan meliputi kunjungan peneliti ke lokasi penelitian untuk melihat kondisi yang sebenamya terkait informasi/data yang dikumpulkan. Kegiatan observasi juga dilakukan ke beberapa sekolah di Kecamatan Kasemen dan Cipocok Jaya.

3. Dokumen yaitu peneliti melakukan analisis dan mengumpulkan data dari dokumen-dokumen tentang pelaksanaan kebijakan wajib belajar pendidikan dasar 9 tahun di Kota Serang meliputi arsip dokumen berupa aturan, perundang-undangan, surat keputusan, rencana kegiatan, foto-foto kegiatan, dan laporan penyelenggaraan wajib belajar 9 tahun.

Analisis data pada penelitian ini melalui tahapan reduksi data, penyajian data, pembahasan dan penarikan kesimpulan. Reduksi data dilakukan dengan memilih, menyederhanakan, pengabstrakan dan transformasi data pada catatan lapangan, proses ini dilakukan selama penelitian berlangsung. Penyajian data pada penelitian ini berbentuk narasi yaitu peneliti menarasikan data dokumen, hasil observasi lapangan, dan wawancara terkait pencapaian tujuan dari kebijakan wajib belajar pendidikan dasar 9 tahun sehingga data yang diperoleh memiliki makna. Jadi, peneliti juga dapat lebih mudah memahami data yang diperoleh. Setiap data yang telah direduksi dan disajikan merupakan simpulan yang masih parsial, d a n tentatif. Verifikasi data merujuk kepada dua pertimbangan, pertama, 
Al-Ishlah: Jurnal Pendidikan - ISSN: 2087-949o (p); 2597-940X (e)

Vol. 12, No. 2 (2020)

simpulan dari data harus dikonfirmasi untuk menjamin data itu benar dan tidak merupakan bagian dari pikiran peneliti.

\section{HASIL DAN PEMBAHASAN}

\section{Hasil Temuan}

Rencana strategi mempengaruhi capaian tujuan pelaksanaan kebijakan wajib belajar 9 tahun di Kota Serang. Konsep-konsep dalam rencana strategis memberikan cara yang mudah untuk mencapai tujuan tersebut. Kerangka penetapan tujuan program wajib belajar 9 tahun di Kota Serang adalah:

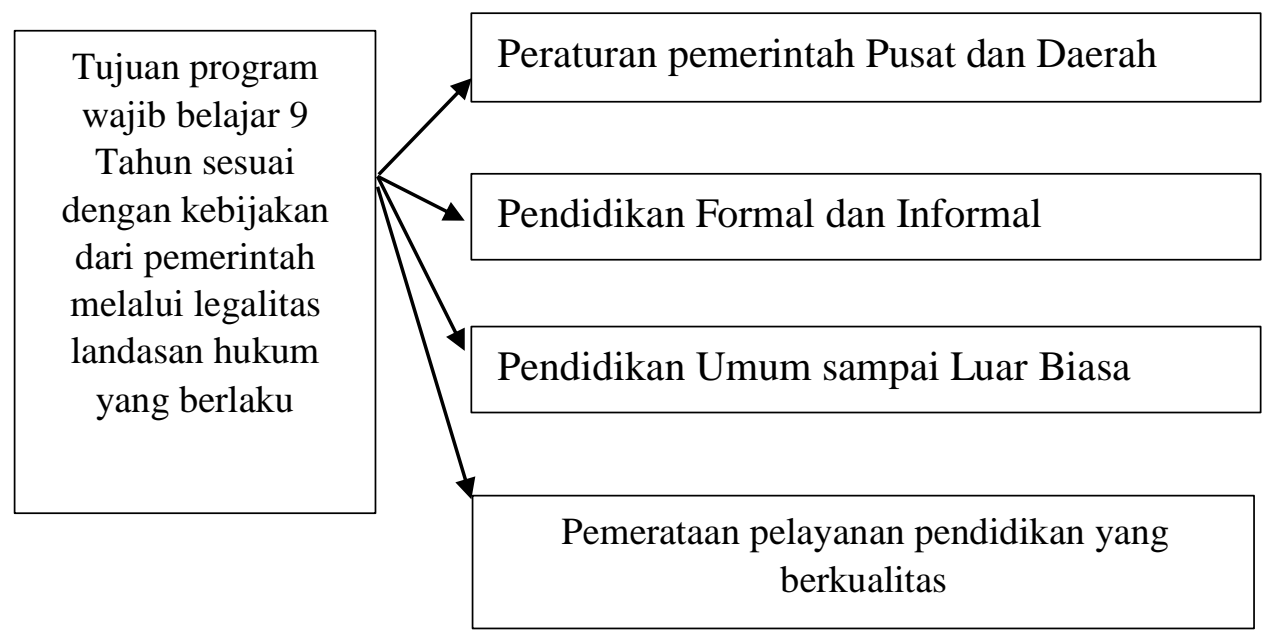

\section{Gambar 1 Kerangka Penetapan Tujuan Program Wajib Belajar 9 Tahun}

Adapun cara-cara yang dilakukan untuk mencapai tujuan penyelenggaraan wajib belajar pendidikan dasar 9 tahun yang berkualitas sebagai berikut;

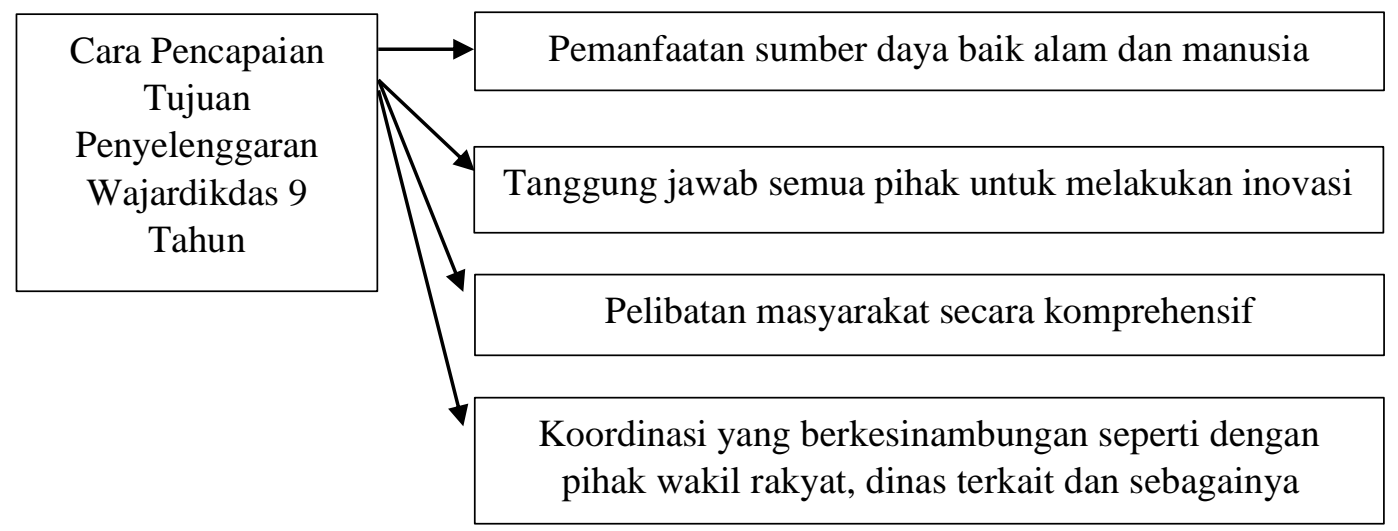

Gambar 2 Cara Pencapaian Tujuan Wajardikdas 9 Tahun 
Vol. 12, No. 2 (2020)

Dinas Pendidikan Kota Serang telah memiliki cara yang cukup baik dalam mencapai tujuan program wajib belajar 9 tahun. Cara-cara tersebut terimplementasi dalam berbagai macam kegiatan yang sesuai kebutuhan di lapangan. Dari paparan tersebut dengan jelas kegiatan-kegiatan yang dilakukan semua pihak untuk mencapai tujuan penyelenggaraan wajib belajar pendidikan dasar 9 tahun yang berkualitas sebagai berikut;

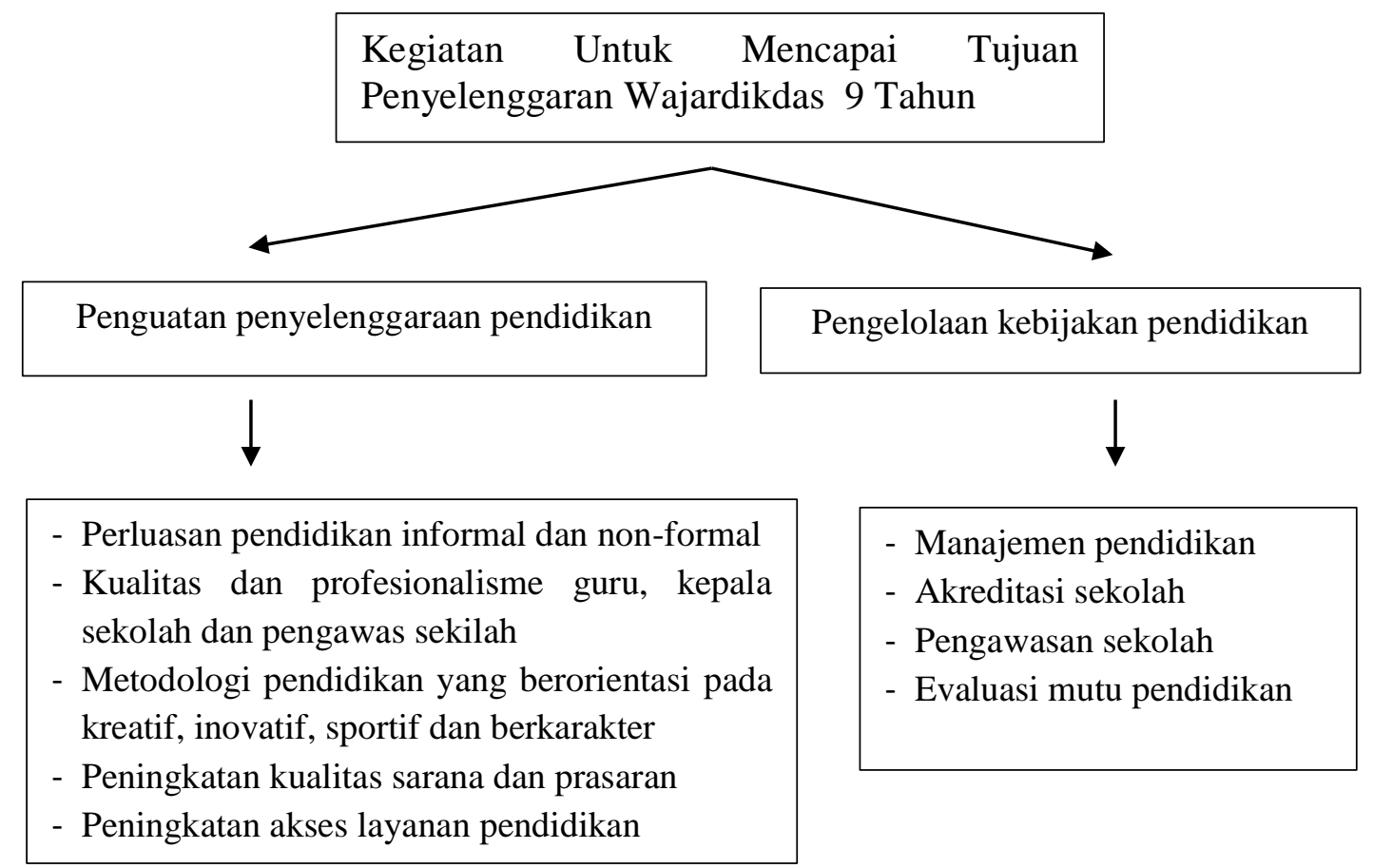

\section{Gambar 3 Kegiatan Untuk Mencapai Tujuan Kebijakan Wajardikdas 9 Tahun dari Indikator Rencana Strategi}

\section{Pembahasan}

Uraian di atas dapat diintisarikan bahwa kegiatan yang dirumuskan dan dilaksanakan dalam rangka mewujudkan pencapaian tujuan penyelenggaraan kebijakan wajib belajar 9 tahun di Kota Serang adalah penguatan dan perluasan pendidikan non formal dan informal, peningkatan kualitas dan profesionalisme guru, kepala sekolah dan pengawas sekolah yang berkelanjutan, pengembangan metodologi pendidikan, peningkatan pencapaian sarana, prasarana dan pembelajaran, penuntasan wajib belajar 9 tahun yang bermutu, peningkatan akses dan pemerataan pelayanan pendidikan, peningkatan mutu, relevansi dan daya saing, peningkatan mutu dan relevansi pendidikan, peningkatan efisiensi manajemen pendidikan, dan peningkatan akreditasi sekolah.

Kriteria evaluasi yang telah ditetapkan adalah adanya kesesuaian antara tujuan penyelenggaraan kebijakan wajib belajar 9 tahun di Kota Serang dengan aturan dan ketentuan yang mengatur tentang penyelenggaraan kebijakan wajib 
Vol. 12, No. 2 (2020)

belajar 9 tahun di Indonesia, antara lain Peraturan Pemerintah Republik Indonesia Nomor 28 Tahun 1990 tentang Pendidikan Dasar dan Peraturan Pemerintah Nomor 47 Tahun 2008 tentang Wajardikdas.

Temuan selanjutnya bahwa pada prinsipnya penyelenggaraan kebijakan wajib belajar 9 tahun adalah untuk mewujudkan amanah Undang-Undang Dasar Negara Republik Indonesia Tahun 1945 yaitu untuk mencerdaskan kehidupan bangsa, serta Undang-Undang Nomor 20 Tahun 2003 tentang Sistem Pendidikan Nasional, yaitu untuk berkembangnya potensi peserta didik agar menjadi manusia yang beriman dan bertaqwa kepada Tuhan Yang Maha Esa, berakhlak mulia, sehat, berilmu, cakap, kreatif, mandiri dan menjadi warga negara yang demokratis dan bertanggung jawab, Salah satu cara untuk mewujudkan amanah dimaksud adalah melalui penuntasan kebijakan wajib belajar 9 tahun yang konsisten, menyeluruh, terukur dan berkualitas. Hasil wawancara menunjukkan aturan-aturan yang dirujuk oleh Dinas Pendidikan di Kota Serang untuk melaksanakan program wajib belajar 9 Tahun di Kota Serang. Maka dapat ditegaskan bahwa tujuan penyelenggaraan kebijakan wajib belajar 9 tahun di Kota Serang telah dilaksanakan secara konsisten dan sungguh-sungguh, berdasarkan aturan dan ketentuan yang telah ditetapkan

Hasil wawancara menyimpulkan bahwa ada empat indikator yang ingin dicapai dalam pelaksanaan wajib belajar 9 Tahun di Kota Serang adalah 1) sudah sesuai dengan peraturan pemerintah pusat dan Kota Serang Banten; 2) memberikan pelayanan pendidikan yang berkualitas, merata dan terakses dengan mudah; 3) penyelenggaraan pendidikan pada jenjang formal maupun informal khususnya dari jenjang Pendidikan Dasar hingga Sekolah Menengah Pertama (SMP/MTs) dan sederajat, agar seluruh anak usia 7-15 tahun di Provinsi Banten memiliki bekal pengetahuan dasar yang cukup untuk dapat bersaing di masyarakat dan sebagai syarat minimal mereka untuk dapat melanjutkan pendidikan ke jenjang Sekolah Menengah Atas. 4) pelaksanaan pendidikan untuk umum dan warga negara yang berkebutuhan khusus (pendidikan luar biasa). Hal ini telah disesuaikan dengan peraturan pemerintah tentang hak setiap warga negara untuk mendapatkan pendidikan. Bagi warga negara yang pernah mengalami putus sekolah, dapat melanjutkan pendidikan penyetaraan agar bisa melanjutkan pendidikan ke jenjang yang lebih tinggi.

Penekanan utama dari pada tujuan yang dirumuskan oleh Dinas Pendidikan Kota Serang adalah memberikan pelayanan pendidikan dasar yang merata dan terakses, agar setiap anak yang telah menyelesaikan pendidikan dasarnya dapat memiliki kemampuan dasar untuk bersaing di masyarakat atau sebagai bekal untuk melanjutkan pendidikan ke jenjang yang lebih tinggi.Oleh karena itu, penetapan dari RPJPD Kota Serang Tahun 2008-2025 mempunyai visi "Terdepan Sebagai Pusat Pendidikan, Jasa, dan Perdagangan 
Al-Ishlah: Jurnal Pendidikan - ISSN: 2087-949o (p); 2597-940X (e)

Vol. 12, No. 2 (2020)

Menuju Kota Serang SMART 2025" Visi ini sangat cocok dengan pelaksanaan kebijakan wajib belajar 9 Tahun dan 12 Tahun. Berdasarkan kerangka berpikir di atas dan hasil telaah kembali membuktikan bahwa relevansi visi Walikota Serang sebagaimana telah disampaikan selama proses Pemilukada tahun 2013, maka visi Kota Serang dalam Perubahan RPJMD Kota Serang Tahun 2014-2018 tetap diarahkan dalam rangka mencapai "Terwujudnya Kota Serang Madani sebagai Kota Pendidikan yang Bertumpu pada Potensi Perdagangan, Jasa, Pertanian, dan Budaya".

Kota Serang sebagai Kota Pendidikan, berupaya merevitalisasi eksistensi Kota Serang yang secara historis pernah menjadi centre of excellent dalam konteks pendidikan, baik pendidikan agama yang berbasis pondok pesantren maupun pendidikan umum yang telah berkembang sejak zaman kolonialisme Belanda. Visi ini relevan untuk ditawarkan, mengingat kondisi terkini Kota Serang yang masih mewarisi sejumlah karakter dan potensi sebagai kota pendidikan. Faktanya, saat ini Kota Serang menjadi destinasi pendidikan agama, dasar dan menengah bagi masyarakat Kota Serang dan sekitarnya, serta destinasi pendidikan tinggi tidak hanya bagi masyarakat Provinsi Banten namun juga telah diakses secara nasional oleh masyarakat dari seluruh penjuru nusantara. Dan seiring dengan perkembangan sektor pendidikan tersebut, maka di masa depan Kota Serang sangat potensial untuk dikembangkan sebagai Kota Pendidikan sebagai salah satu jati dirinya.

Pada evaluasi kebijakan wajib belajar 9 tahun di Kota Serang, tujuan pendidikan dasar yang dirumuskan oleh seluruh instansi pendidikan merupakan faktor kunci yang sangat berperan dalam merancang suatu rencana aksi dan capaian pada saat yang akan datang untuk membawa seluruh pemangku kepentingan pada situasi dan kondisi ideal yang dikehendaki yaitu tuntasnya pendidikan dasar yang berkualitas di Kota Serang. Maknanya adalah bahwa tujuan tentang pendidikan dasar harus dirumuskan secara cermat dan tepat karena pendidikan dasar merupakan titik awal atau tonggak pendidikan yang sangat penting (golden moment) bagi perkembangan potensi setiap anak untuk dapat lebih maju sesuai tuntutan zaman dan teknologi modern yang terus berkembang pesat.

Secara garis besar, inti daripada pencapaian tujuan penyelenggaraan kebijakan wajib belajar 9 tahun di Kota Serang adalah pemanfaatan semua sumber daya yang dimiliki dan inovasi baru yang perlu dipikirkan agar dapat semaksimal mungkain digunakan dalam penyelenggaraan pendidikan dasar yang tuntas, terakses, adil dan merata. Dukungan dari semua pihak yang telah terlibat menjadi faktor utama dalam pencapaian tujuan kebijakan wajib belajar 9 Tahun. 
Banyak keberhasilan program wajib belajar 9 tahun di Kota Serang. Beberapa negara lain pun telah memberlakukan program wajib pendidikan bagi warganya. Negara wajib memberikan fasilitas pendidiksan gratis bagi warganya untuk memperkuat ketahanan nasional (Ahmadi \& Laei, 2012). Apalagi Ketika biaya pendidikan begitu mahal, maka negara harus membantu penyelenggaran pendidikan warganya (Cai, Chen, \& Zhu, 2017). Setiap warga negara berhak memilih pendidikan yang diinginkan untuk meningkatkan kualitas hidup (Solstad \& Andrews, 2020). Pendidikan adalah elemen penting dalam meningkatkan kesadaran siswa tentang lingkungan. Di negara lain, pelaksanaan kebijakan wajib belajar juga telah dilakukan untuk meningkatkan kualitas. Berbagai upaya yang digunakan untuk merubah sistem pendidikan (Mróz, Ocetkiewicz, \& Tomaszewska, 2020). Reformasi sistem pendidikan yang memberikan hasil sangat baik contohnya pada negara Finlandia (Risku, 2014). Sistem pendidikan di Finlandia dilakukan secara terpusat. Sistem pendidikan dilakukan secara komprehensif (Kauko, 2019).

\section{SIMPULAN}

Stakeholder di Dinas Pendidikan Kota Serang telah merancang berbagai cara dan kegiatan untuk mencapai tujuan dari implementasi kebijakan Wajardikdas 9 Tahun. Langkah yang diambil oleh stakeholder telah sesuai dengan kemampuan dan karakteristik dari Kota Serang. Penerapan kegiatan yang telah teridentifikasi juga telah disesuaikan dengan kebutuhan dalam penyelenggaraan pendidikan dasar di Kota Serang agar sesuai dengan karakteristik kehidupan sosial masyarakat di Kota Serang. Pemerintahan Dinas Pendidikan Kota Serang berupaya melaksanakan kebijakan Wajardikdas 9 tahun sesuai dengan Undangundang dan PP yang disesuaikan dengan visi misi Kota Serang. Tujuan dari kebijakan ini telah tercapai walaupun pemerintahan Kota Serang masih menghadapi beberapa kendala untuk mencapai tujuan sesuai pda PP No.47 Tahun 2008.

Rekomendasi yang diberikan kepada dinas pendidikan Kota Serang dari hasil penelitian ini antara lain:

a) Melibatkan komite sekolah dalam melakukan monitoring dan penilaian dari setiap program untuk mengimplementasikan kebijakan wajardikdas 9 tahun secara berkala dan terstruktur

b) Melibatkan masyarakat sebagai komunitas lokal untuk terlibat dalam berbagai kegiatan untuk implementasi kebijakan wajardikdas 9 tahun

c) Pemerintah melalui dinas pendidikan Kota Serang sebaiknya melibatkan industri, masyarakat, orang tua, dan sekolah dalam membangun kurikulum pelaksanaan pendidikan agar sesuai dan dapat memenuhi kebutuhan daerah serta tantangan global. 
Al-Ishlah: Jurnal Pendidikan - ISSN: 2087-949o (p); 2597-940X (e)

Vol. 12, No. 2 (2020)

Sesuai hasil evaluasi terhadap capaian ketuntasan dalam penyelengggaraan program wajardikdas 9 tahun di Kota Serang, beberapa rekomendasi untuk pihak sekolah baik tingkat sekolah dasar atau menengah antara lain;

a) Meningkatkan mutu lulusan ujian nasional melalui perbaikan pola belajar mengajar khususnya untuk mata pelajaran yang nilai ujiannya masih rendah.

b) Pemberian pemamahan materi dan bahan ajar serta buku-buku pengayaan yang lebih lengkap dan terkini.

c) Sekolah melibatkan teknologi dalam proses belajar mengajar

d) Sekolah selalu melakukan rapat dengan para orang tua dan komite sekolah untuk menentukan kebijakan ataupun perubahan yang berkaitan dengan proses belajar mengajar

\section{DAFTAR PUSTAKA}

Ahmadi, A., \& Laei, S. (2012). Public Education: Compulsory and Free? A Paradox. Procedia - Social and Behavioral Sciences, 47, 868-873. https://doi.org/10.1016/j.sbspro.2012.06.749

Akbar, M. F. (2016). Evaluasi Kebijakan Program Pemberian Dana Bantuan Operasional Sekolah. Jurnal Analisis Dan Pelayanan Publik, 2(1).

Anti, A. (2015). IMPLEMENTASI PROGRAM WAJIB BELAJAR 9 TAHUN DI PEKANBARU TAHUN 2012. Jom FISIP, 2(2).

Ary, D., Jacobs, L. C., Sorensen, C., \& Razavieh, A. (2010). Introduction to Research in Education (8 Edition). CA: Cengage Learning.

Aziz, S., Mahmood, M., \& Rehman, Z. (2018). Implementation of CIPP Model for Quality Evaluation at School Level: A Case Study. Journal of Education and Educational Development, 5(1), 189. https://doi.org/10.22555/joeed.v5i1.1553

Cai, W., Chen, G., \& Zhu, F. (2017). Has the compulsory school merger program reduced the welfare of rural residents in China? China Economic Review, 46, 123-141. https://doi.org/10.1016/j.chieco.2017.07.010

Darma, I. K. (2019). The effectiveness of teaching program of CIPP evaluation model. International Research Journal of Engineering, IT \& Scientific Research, 5(3), 1-13. https://doi.org/10.21744/irjeis.v5n3.619

Jin, Y., \& Zhang, H. (2008). Research on the Costs of Running Compulsory Education Standards: Comparison of Compulsory Education Internationally. International Education Studies, 1(3).

Kauko, J. (2019). The Finnish Comprehensive School. In Great Policy Successes (pp. 122-142). Oxford University Press. https://doi.org/10.1093/oso/9780198843719.003.0007

Lu, C. H. (2018). Social status, compulsory education, and growth. Economic 
Al-Ishlah: Jurnal Pendidikan - ISSN: 2087-949o (p); 2597-940X (e)

Vol. 12, No. 2 (2020)

Modelling, 68(June), 425-434.

https://doi.org/10.1016/j.econmod.2017.08.013

Mróz, A., Ocetkiewicz, I., \& Tomaszewska, B. (2020). What should be included in education programmes - The socio-education analysis for sustainable management of natural resources. Journal of Cleaner Production, 250, 119556. https://doi.org/10.1016/J.JCLEPRO.2019.119556

Mugiri, \& Lestari, W. (2013). INSTRUMEN EVALUASI PROGRAM DANA BOS MODEL CIPP. Journal of Educational Research and Evaluation, 2(1).

Pemerintah Republik Indonesia. (2008). PP Nomor 47 Tahun 2008 tentang Wajib Belajar. PP Nomor 47 Tahun 2008 Tentang Wajib Belajar, 1-12. https://doi.org/10.1017/CBO9781107415324.004

Risku, M. (2014). A Historical Insight on Finnish Education Policy from 1944 to 2011. Italian Journal of Sociology Of, (June).

Solstad, K. J., \& Andrews, T. (2020). From rural to urban to rural to global: 300 years of compulsory schooling in rural Norway. Journal of Rural Studies, 74, 294-303. https://doi.org/10.1016/j.jrurstud.2019.10.034

Warju, W. (2016). Educational Program Evaluation using CIPP Model.

Innovation of Vocational Technology Education, 12(1).

https://doi.org/10.17509/invotec.v12i1.4502 